\title{
Clinical Characteristics of Coronavirus Disease 2019 in Hainan, China
}

Shijiao Yan, $\mathrm{PhD}^{1,2 \#}$, Xingyue Song, $\mathrm{PhD}^{3,4 \#}$, Feng Lin, MD ${ }^{5 \#}$, Haiyan $\mathrm{Zhu}^{\#}$, MD ${ }^{6}$, Xiaozhi Wang, MD ${ }^{7 \#}$, Min Li, MD ${ }^{8 \#}$, Jianwen Ruan, MD ${ }^{9 \#}$, Changfeng Lin, MD ${ }^{10 \#}$, Xiaoran Liu, $\mathrm{MD}^{2,11}$, Qiang $\mathrm{Wu}, \mathrm{PhD}^{2,4}$, Zhiqian Luo, $\mathrm{MS}^{4,12}$, Wenning $\mathrm{Fu}, \mathrm{PhD}^{13}$, Song Chen, $\mathrm{MD}^{4,11}$, Yong Yuan, $\mathrm{MD}^{2,4}$, Shengxing Liu, $\mathrm{MD}^{14}$, Jinjian Yao, MD ${ }^{2,15}$, Chuanzhu Lv, MD, MS $\mathrm{M}^{4,7,14}$

${ }^{1}$ School of Public Health, Hainan Medical University, Haikou, Hainan, China.

${ }^{2}$ Research Unit of Island Emergency Medicine, Chinese Academy of Medical Sciences (No. 2019RU013), Hainan Medical University, Haikou, Hainan, China;

${ }^{3}$ Department of Epidemiology and Biostatistics, and Ministry of Education Key Laboratory of Environment and Health, and State Key Laboratory of Environmental Health (Incubating), School of Public Health, Tongji Medical College, Huazhong University of Science and Technology, Wuhan, Hubei Province, China;

${ }^{4}$ Key Laboratory of Emergency and Trauma of Ministry of Education, Hainan Medical University, Haikou, Hainan, China;

${ }^{5}$ Department of Infectious Diseases, Hainan General Hospital, Hainan Affiliated Hospital of Hainan Medical University, Haikou, China;

${ }^{6}$ Emergency Department, the First Medical Center of Chinese PLA General Hospital, Beijing, China;

${ }^{7}$ Department of Emergency, Hainan Clinical Research Center for Acute and Critical Diseases, The Second Affiliated Hospital of Hainan Medical University, Haikou, Hainan, China;

${ }^{8}$ The Second Naval Hospital of Southern Theater Command of PLA, Sanya, Hainan, China; 
${ }^{9}$ Department of Infectious Diseases, Haikou Municipal People's Hospital, Haikou, Hainan, China;

${ }^{10}$ The Third People's Hospital of Hainan Province, Sanya, Hainan, China

${ }^{11}$ Emergency Department, the First Affiliated Hospital of Hainan Medical University, Haikou, Hainan, China;

${ }^{12}$ Trauma Center, the First Affiliated Hospital of Hainan Medical University, Haikou, Hainan, China;

${ }^{13}$ School of Nursing, Tongji Medical College, Huazhong University of Science and Technology, Wuhan, China;

${ }^{14}$ Emergency and Trauma College, Hainan Medical University, Haikou, Hainan, China;

${ }^{15}$ Department of emergency, Hainan General Hospital, Hainan Affiliated Hospital of Hainan Medical University, Haikou, China.

\# These authors contributed equally to this work.

\section{*Correspondence to:}

Jinjian Yao, MD, Department of emergency, Hainan General Hospital, Hainan Affiliated Hospital of Hainan Medical University, Haikou, China.

Chuanzhu Lv, MD, Department of Emergency, Hainan Clinical Research Center for Acute and Critical Diseases, The Second Affiliated Hospital of Hainan Medical University, No. 3 Xueyuan Road, Longhua Zone, Haikou 571199, China. Phone and fax numbers: +86-898-66989169; E-mail: lvchuanzhu677@126.com. 


\begin{abstract}
Background: Since January 2020, coronavirus disease 2019 (Covid-19) has spread rapidly and developing the pandemic model around the world. Data have been needed on the clinical characteristics of the affected patients in an imported cases as model in island outside Wuhan.
\end{abstract}

Methods: We conducted a retrospective study included all 168 confirmed cases of Covid-19 in Hainan province from 22 January 2020 to 13 March 2020. Cases were confirmed by real-time RT-PCR and were analysed for demographic, clinical, radiological and laboratory data.

Results: Of 168 patients, 160 have been discharged, 6 have died and 2 remain hospitalized. The median age was 51.0 years and $51.8 \%$ were females. $129(76.8 \%)$ patients were imported cases, and 118 (70.2\%), 51 (30.4\%) and $52(31 \%)$ of patients lived in Wuhan or traveled to Wuhan, had contact with Covid-19 patients, or had contact with Wuhan residents, respectively. The most common symptoms at onset of illness were fever (65.5\%), dry cough (48.8\%) and expectoration (32.1\%). On admission, ground-glass opacity was the most common radiologic finding on chest computed tomography $(60.2 \%)$. The elderly people with diabetes, hypertension and CVD are more likely to develop severe cases. Follow-up of 160 discharged patients found that 20 patients $(12.5 \%)$ had a positive RT-PCR test results of pharyngeal swabs or anal swabs or fecal.

Conclusions: In light of the rapid spread of Covid-19 around the world, early diagnosis and quarantine is important to curb the spread of Covid-19 and intensive 
medRxiv preprint doi: https://doi.org/10.1101/2020.03.19.20038539; this version posted March 23, 2020. The copyright holder for this preprint (which was not certified by peer review) is the author/funder, who has granted medRxiv a license to display the preprint in perpetuity.

All rights reserved. No reuse allowed without permission.

treatments in early stage is to prevent patients away from critical condition. 


\section{Introduction}

In December 2019, patients with pneumonia of unknown causes were found in some medical institutions in Wuhan, Hubei province, China. ${ }^{1}$ On January 7, 2020, the virus was isolated from a sample of a positive patient and the entire genome sequence of the virus was obtained. ${ }^{2}$ Subsequent studies indicated that the virus belonged to the type b coronavirus family, and its genetic characteristics were obviously different from Severe Acute Respiratory Syndrome (SARS) and Middle East Respiratory Syndrome (MERS). ${ }^{3,4}$ The World Health Organization (WHO) declared the new coronavirus pneumonia as a public health emergency of international concern on 31 January 2020, and officially named it "coronavirus disease 2019 (Covid-19)"on February 11, 2020. Covid-19 is mainly transmitted from human-to-human by respiratory droplets and close contact, and may also be transmitted through fecal mouth and aerosol. ${ }^{5,6}$ The clinical manifestations of Covid-19 are very similar to SARS, and patients may develop acute respiratory distress syndrome (ARDS), which is highly likely to require intensive care and even lead to death. ${ }^{7}$ Since January 2020 , the Covid-19 has spread rapidly from Wuhan to other parts of China and other countries around the world. ${ }^{8-10}$ As of March 13, 2020, a total of 132,758 laboratory-confirmed cases (80,991 in China) and 4955 deaths (3180 in China) had been reported worldwide. ${ }^{11}$ With the increasing number of confirmed and suspected cases globally, the situation of disease prevention and control is extremely critical.

Since the outbreak of Covid-19, several studies have successively reported the clinical characteristics of patients infected with Covid-19, but almost all the research 
was conducted in Wuhan or other cities in inland China. ${ }^{12-15}$ Hainan province is an independent island located at the southern tip of China, unlike the rest of China, Hainan province belongs to tropical monsoon climate. Previous studies have found that climate affects the spread of SARS virus. ${ }^{16}$ Therefore, we describe the clinical characteristics and laboratory findings of patients infected with Covid-19 in Hainan province to explore whether it is different from other regions in China, and to provide an insight into the prevention and treatment of Covid-19 across China, especially to other places with similar climate and environment as Hainan province.

\section{Methods}

\section{Study Design and Participants}

We conducted a retrospective study focusing on the clinical characteristics of confirmed cases of Covid-19 in Hainan province from 22 January 2020 (the time of the first confirmed patient in Hainan province) to 14 March 2020. Sputum and throat swab specimens collected from all patients at admission were tested by real time polymerase chain reaction for SARS-Cov-2 RNA. All patients with Covid-19 were diagnosed based on the WHO interim guidance ${ }^{17}$ and the "Diagnosis and Treatment of New Coronavirus Pneumonia (trial version 3)" published by National Health Commission of the People's Republic of China. ${ }^{18}$ A confirmed case was defined as a positive result to high-throughput sequencing or real-time reverse-transcriptase polymerase-chain-reaction (RT-PCR) assay for nasal and pharyngeal swab specimens. ${ }^{7}$ Only the laboratory-confirmed cases were included in the analysis.

The study was approved by the institutional ethics board of the Second Affiliated 
Hospital of Hainan Medical University (No. 2020R003). Written informed consent was waived due to the urgent need to collect clinical data on this emerging disease.

\section{Data Collection}

All medical records of patients were extracted by a doctor assigned by local hospital and sent to the data processing center in Haikou. A team of experienced respiratory clinicians reviewed and abstracted the data. Data were entered into a computerized database and cross-checked. If the data were with mission or doubt, the coordinators in Haikou contacted the doctor who is responsible for the treatment of the patient for clarification.

The epidemiological characteristics (demographic data, exposure history, and underlying comorbidities), clinical (symptoms and signs), laboratory (ie, complete blood count, blood chemistry, coagulation test, liver and renal function, electrolytes) and radiological findings (chest X-ray or computed tomography), treatment (ie, antiviral therapy, corticosteroid therapy, respiratory support) and outcomes (remained in hospital, discharges, death) data were extracted from electronic medical records. The severity of Covid-2019 was defined based on the "Diagnosis and Treatment of New Coronavirus Pneumonia (trial version 7)” published by National Health Commission of the People's Republic of China. ${ }^{19}$ Severe patients are defined as having been critically ill during their hospitalization. Fever was defined as an axillary temperature of $37.3^{\circ} \mathrm{C}$ or higher. Acute respiratory distress syndrome (ARDS) was defined according to the Berlin definition. ${ }^{20}$ Acute kidney injury was identified according to the Kidney Disease: Improving Global Outcomes definition. ${ }^{21}$ Cardiac 
injury was defined if the serum levels of cardiac biomarkers (eg, troponin I) were above the 99th percentile upper reference limit or new abnormalities were shown in electrocardiography and echocardiography. ${ }^{22}$ The durations from onset of disease to first hospital visit, admission, severe, discharge or death were recorded. The clinical outcomes were monitored up to March 13, 2020, the final date of follow-up.

\section{Statistical Analysis}

Categorical variables were presented as the counts and percentages in each category, and chi-square tests and Fisher's exact tests were used for comparing as appropriate. Continuous variables were presented as medians and interquartile ranges (IQR) and compared with Wilcoxon rank-sum tests. All analyses were performed using SPSS (Statistical Package for the Social Sciences) version 22.0 software (SPSS Inc), and the statistical significance was two-sided $P$ values $<0.05$. Distribution map was plotted using ArcGis version 10.2.2

\section{Results}

As of March 13, 2020, a total of 168 patients (Non-severe: 132; Severe: 36) were infected with Covid-19 in Hainan province. The distribution of patients infected with Covid-19 across Hainan province is presented in Figure 1. The demographic and clinical characteristics of patients by severity group are presented in Table 1 . The median age was 51.0 years (IQR, 36-62), 51.8\% were females and 33.3\% were the retired. $129(76.8 \%)$ patients were imported cases, and $118(70.2 \%), 51(30.4 \%)$ and $52(31 \%)$ of the patients lived in Wuhan or traveled to Wuhan, had contact with Covid-19 patients, or had contact with Wuhan residents, respectively. 


\section{Figure 1 Distribution of Patients infected with Coronavirus Disease 2019 across}

\section{Hainan Province}

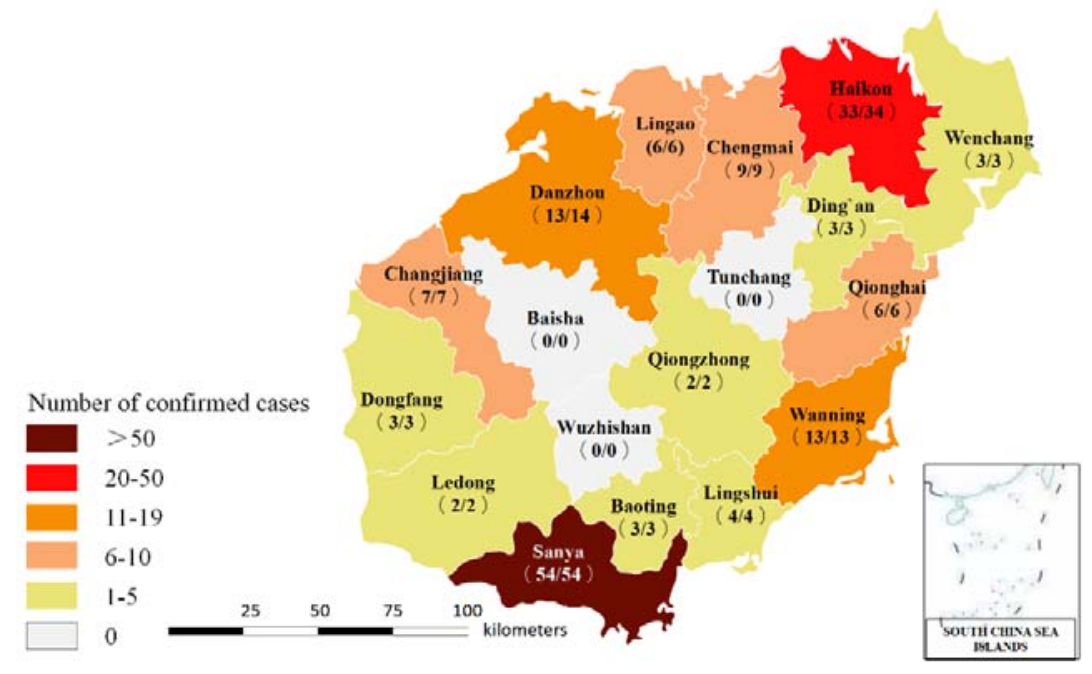

The numerator denotes the number of discharge patients and the denominator denotes the number of laboratory-confirmed cases

The most common symptoms at onset of illness were fever (65.5\%), dry cough (48.8\%) and expectoration (32.1\%), while rhinorrhea (3.6\%), abdominal pain (4.2\%), vomiting (4.2\%), dyspnea (4.2\%), arthralgia (1.2\%), pharyngeal congestion $(0.6 \%)$, pharyngeal discomfort (4.2\%), dry throat (3.0\%), shortness of breath $(2.4 \%)$ and hemoptysis $(0.6 \%)$ were rare. On admission, $24(14.3 \%), 12(7.1 \%)$, and $12(7.1 \%)$ patients are with history of hypertension, diabetes, and cardiovascular disease, respectively.

Compared with non-severe patients, severe patients were significantly older (median, 61 years vs 49 years; $P<0.05$ ), were more likely to have higher temperature 
(median, $37.0^{\circ} \mathrm{C}$ vs $36.8^{\circ} \mathrm{C} ; P<0.05$ ) and heart rate (median, $92.0 \mathrm{bpm}$ vs $80.5 \mathrm{bpm}$; $P<0.05)$ on admission, and more likely to have underlying comorbidities, including hypertension $(30.6 \%$ vs $9.8 \% ; P<0.05)$, diabetes $(19.4 \%$ vs $3.8 \% ; P<0.05)$ and cardiovascular disease (CVD) $(16.7 \%$ vs $4.5 \% ; P<0.05)$.

\section{Radiologic and Laboratory Findings}

The radiologic and laboratory findings on admission are shown in Table 2. Of 133

patients who underwent chest computed tomography (CT), the most common patterns were ground-glass opacity (60.2\%) and bilateral patchy shadowing (42.9\%). Of 51 patients who underwent chest X-ray, the most common patterns were bilateral patchy shadowing (35.3\%) and local patchy shadowing (31.4\%). Typical chest CT findings of infected patients on admission were shown in Figure 2. 
Figure 2. Chest Computed Tomographic Images of a 50-Year-Old Severe Patient Infected With Coronavirus Disease 2019 A Computed tomography images on day 10 after symptom onset
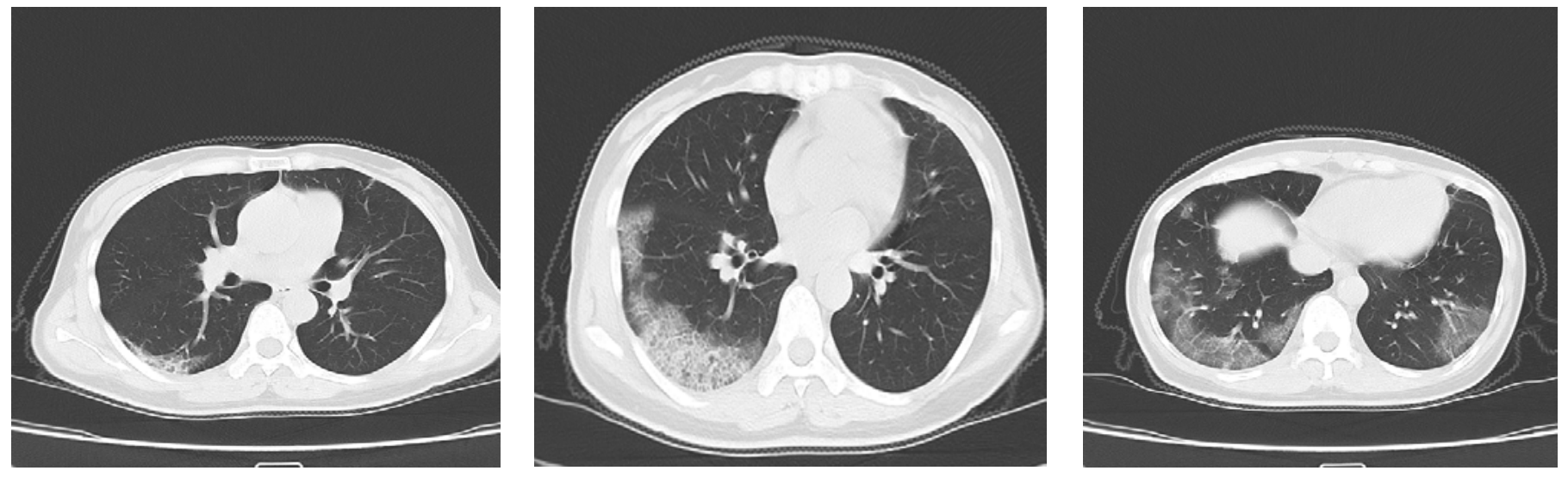

B Computed tomography images after treatment on day 23 after symptom onset
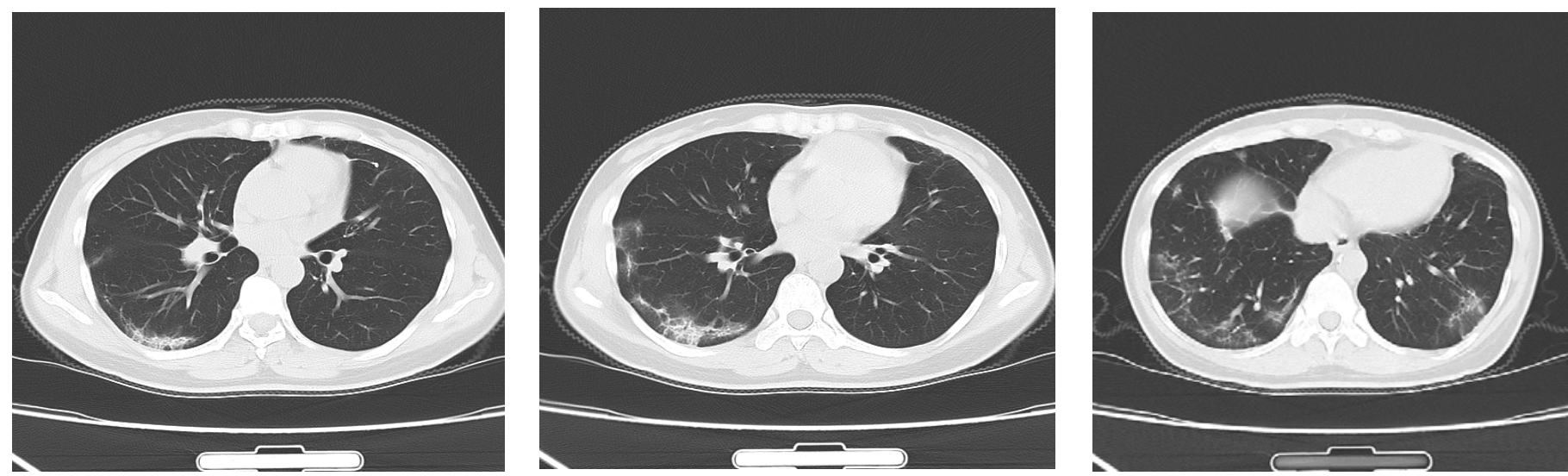
A, Chest computed tomographic images obtained on February 10, 2020, show ground glass opacity in both lungs on day 10 after symptom onset.

B, Images taken on February 23, 2020, show fibrous cord shadows in both lungs, and the absorption of inflammation. 
On admission, the levels of lymphocyte, white blood cell and neutrophil were decreased in $72(72 \%)$ of 165 patients, $40(24 \%)$ of 167 patients and $19(11.4 \%)$ patients, respectively, while the levels of C-reactive protein, D-dimer, prothrombin time and activated partial thromboplastin time were increased in 65 (67\%) of 97 patients, $14(30.4 \%)$ of 46 patients, $10(10.5 \%)$ of 95 patients and $8(8.3 \%)$ of 96 patients, respectively. There were numerous differences in laboratory findings between non-severe patients and severe patients, including white blood cell count, platelet count, lymphocyte ratio, neutrophil ratio, lymphocyte count, neutrophil count, eosinophil count, C-reactive protein, D-dimer, chloride, calcium, total protein, albumin, aspartate aminotransferase, lactate dehydrogenase, total bilirubin and procalcitonin (All $P<0.05)$. The dynamic changes in 6 clinical laboratory parameters of 36 severe patients, including hematological and biochemical parameters were shown in Supplemental Figure 1.

\section{Clinical Outcomes, Complications and Treatment}

Of the all 168 patients, 160 have been discharged, 6 have died and 2 remain hospitalized (Table 3). The median time from onset of symptoms to first hospital visit, diagnosis and hospital admission was 1 day (IQR, 0-4), 4.5 days (IQR, 2-7) and 5 days (IQR, 2-7), respectively (Table 4). For severe patients, the median time from onset of symptoms to severe illness was 11 days (IQR, 7-13). For discharged patients, the median time from onset of symptoms to discharged was 22 days (IQR, 17-27), and the median time from hospital admission to discharged was 17 days (IQR, 12-21). For dead patients, the median time from onset of symptoms to death 
was 17 days (IQR, 10.5-37.3), and the median time from hospital admission to death was 13 days (IQR, 1.5-28.3). Follow-up of 160 discharged patients found that 20 patients $(12.5 \%)$ had a positive RT-PCR test results of pharyngeal swabs or anal swabs or faeces.

During hospital admission, the common complication was ARDS (10.1\%), secondary bacterial pneumonia (7.1\%) and shock (4.2\%). Compared with non-severe patients, severe patients are more prone to almost all complications. During the hospital admission, $97(57.7 \%)$ and $13(7.7 \%)$ patients received nasal catheter oxygen and non-invasive ventilator assisted breathing, respectively. Trachea cannula and tracheotomy were performed in 10 and 2 severe patients, respectively. 155 (92.3\%) patients received antiviral treatment, 119 (70.8\%) were given antibiotic treatment, $91(54.2 \%)$ were given immunopotentiator, $71(42.3 \%)$ patients received intestinal flora regulating drugs, and $27(16.1 \%)$ were given glucocorticoid.

\section{Discussion}

Hainan province as a tropical island in southern China, the aged from the north and middle part of China prefer to spend their winter in Hainan province due to the warmest winter in China at end of every year, especially a part of them has pulmonary, cardiac, metabolic disease. The conditions shaped the epidemic and morbidity of Covid-19 and the demographics and clinical profile of Covid-19 patients distinctive from other places of China. To our knowledge, we first exemplify the Covid-19 outbreak of a real island scenario in an imported Covid-19 epidemic model for worldwide. To date, there are 168 confirmed cases in Hainan province, 
including 129 (76.8\%) imported cases. 36 (21.4\%) patients developed into severe illness after admission to the designated hospital, and fatality rate was $3.6 \%$.

The rate of severe illness and death in our study were higher than a study conducted in the multicenter ${ }^{23}$ and a study conducted in Wenzhou, Zhejiang province, ${ }^{12}$ but lower than studies conducted in Wuhan. ${ }^{7,14,15}$ The reason may be that a large number of elderly people come to Hainan at end of each year for avoiding cold winter. $55(32.7 \%)$ patients over 60 years old in our study, this group may have more comorbidities, and more likely to develop into severe illness once infected with Covid-19. Consistent with previous findings, ${ }^{15,23}$ we found that the older and patients with comorbidities (hypertension, diabetes and CVD) were more likely to develop severe illness. All death in patients (5 imported cases and 1 local case) have a kind of comorbidity, 2 of them have two comorbidities. The possible reason may be the chronic course of hypertension and diabetes leading consistent damage to the micro-vascular walls, resulting in both inefficacy of immune cell infiltration and drug deliver into lung areas. ${ }^{24,25}$ In our study, 8 patients were young patients aged 0 to 17 years, the youngest was 3 months and 19 days, and the oldest was 17 years old. The 8 adolescent patients were all relatively mild without significant changes in radiology and laboratory test, moreover, none of them progressed to critical ill case, similar results have also reported in another study conducted in Guangzhou. ${ }^{26}$ The mechanism responsible for this phenomenon is not clear yet and further research is needed to explore the possible causes.

In consistence with previous studies, fever, dry cough and expectoration were 
the most common symptoms in our study, and it's worth noting that not all patients infected with Covid-19 had fever, or fever at initial stage. ${ }^{23,27}$ Fever, as an alarm syndrome, is less frequent in Covid-19 than other coronavirus (MERS and SARS), so more attention should be paid to Covid-19 patients without fever for their role as source of infection. Moreover, vomit and high fever (>39.0) is related to severe case on admission and during hospitalization in our analysis.

The radiological abnormalities are a part of diagnosis, all patients have lesion in radiology, and the radiological progression of Covid-19 in severe patient is gradual. The initial radiological lesion are patchy shadows in bilateral or unilateral lower lungs in outer bands, and then progress to $1 / 3$ of both lower lungs, then involve both upper lungs, and eventually develop into "white lung". In considering of Covid-19 pneumonia progression and 4 or 5 days interval from symptoms onset to diagnosis, a lung CT scan or X-ray routinely in every 3 or 4 days were recommended for the evaluating progression and early diagnosis of Covid-19.

In concert with recent studies in laboratory tests, ${ }^{7,14,23,28}$ lymphopenia, thrombocytopenia and neutrocytosis in severely ill ones suggest the acute mix-infections of bacteria, virus, and even fungi, the activation of circulating immune cell could amplify immune response cascade, inducing both immune cell and cytokine storm, therefore increasing chances of developing septic shock and the organs failure. Interestingly, the decrease of eosinophils is pronounced in severe patients in our study, and eosinophil counts are even lower in some critically ill patients. Despite the fact that use of glucocorticoids would lead to eosinophilia, we 
still observed this feature in patients without glucocorticoids administration, the previous study also demonstrated that eosinophils percentage related the severity of Covid-19 pneumonia. ${ }^{28}$ The decrease in eosinophil count may be an important predictor of critically ill patients, the subsequent clinical feature analysis should validate the predictability of eosinophil. Abnormalities in organs function and internal disturbance focused on coagulation, liver function and electrolyte system. Increase of D-dimer and decrease serum level of chloride and calcium occurred in critically ill patients, indicating coagulation disorders secondary to inflammatory cascade after severe infection and electrolyte disturbances. The oxygen therapies are of vital importance for the progressive Covid-19, because ARDS is common complication in severe Covid-19 patients, the $\mathrm{PaO}_{2} / \mathrm{FiO}_{2}$ ratio is clinical predictor in both severity and mortality. The $\mathrm{PaO} 2 / \mathrm{FiO} 2$ ratio of Cocid-19 patients indicated the effect of oxygenation and the response to current therapies against hypoxemia.

For the critical illness in adults in Hainan, the common reason of severe patients bears a long waiting time for diagnosis and intensive treatments, including a long time from onset to consultation or a long time from the suspect to laboratory-confirmed. The rapid progress in severe patients illustrates the importance of shorten time of each step, so a bundle of consecutive steps including early test, early diagnosis, early isolation, and early treatment for Covid-19 patients might have contributed to a favorable outcome.

Among 160 discharged patients with Covid-19 infection who met the criteria for hospital release of quarantine, 20 of them conversed to positive RT-PCR test 
results without any clinical symptoms after 3 to34 days after discharge. At present, the cause of the returning positive of RT-PCR still remains unclear, though there were no evidence shows that kind of patients have the infectivity, we still suggest the current standards for hospital discharge should be reevaluated, and the detection and management of discharged patients should be strengthened.

Our study has some limitations. First, though we have included all the patients of Covid-19 in Hainan province, the sample size was still relatively small and the patients were only from Hainan province, it might be that more clinical features related to Covid-19 would not be identified yet. Secondly, some cases had incomplete record of the radiologic and laboratory testing, given the different procedures among different hospitals.

In conclusion, patients infected with Covid-19 have a severe rate of $21.4 \%$ and a fatality rate of $3.6 \%$ in Hainan province. The elderly people with diabetes, hypertension and CVD are more likely to develop severe cases. Fever is the most common symptom, though it does not occur in all patients before hospital admission. In light of the rapid spread of Covid-19 around the world, and no specialized medication to treat Covid-19, early identification and diagnosis is important for the prevention and treatment of Covid-19 to prevent patients from developing into critical illness. 
medRxiv preprint doi: https://doi.org/10.1101/2020.03.19.20038539; this version posted March 23, 2020. The copyright holder for this preprint

(which was not certified by peer review) is the author/funder, who has granted medRxiv a license to display the preprint in perpetuity.

All rights reserved. No reuse allowed without permission.

\section{Funding}

This study funded by Chinese Academy of Medical Sciences Innovation Fund for

Medical Sciences (2019-I2M-5-023), Hainan Provincial Science and Technology

Major Project (ZDKJ201804) and Hainan Social Development Fund

(ZDYFXGFY2020004). The funders had no role in study design, data collection and analysis, decision to publish, or preparation of the manuscript.

\section{Acknowledgements}

We thank all the hospital staff members for their efforts in collecting the information that was used in this study, and Chinese Academy of Medical Sciences for the support. 


\section{Reference}

1. Lu H, Stratton CW, Tang YW. Outbreak of pneumonia of unknown etiology in Wuhan, China: The mystery and the miracle. J Med Virol 2020;92:401-2.

2. Chan JF, Kok KH, Zhu Z, et al. Genomic characterization of the 2019 novel human-pathogenic coronavirus isolated from a patient with atypical pneumonia after visiting Wuhan. Emerg Microbes Infect 2020;9:221-36.

3. Zhu N, Zhang D, Wang W, et al. A Novel Coronavirus from Patients with Pneumonia in China, 2019. N Engl J Med 2020;382:727-33.

4. Zhou P, Yang XL, Wang XG, et al. A pneumonia outbreak associated with a new coronavirus of probable bat origin. Nature 2020.

5. Special Expert Group for Control of the Epidemic of Novel Coronavirus Pneumonia of the Chinese Preventive Medicine Association. An update on the epidemiological characteristics of novel coronavirus pneumonia (COVID-19). Chinese Journal of Epidemiology 2020;41:139-44.

6. Li Q, Guan X, Wu P, et al. Early Transmission Dynamics in Wuhan, China, of Novel Coronavirus-Infected Pneumonia. N Engl J Med 2020.

7. Huang C, Wang Y, Li X, et al. Clinical features of patients infected with 2019 novel coronavirus in Wuhan, China. Lancet 2020;395:497-506.

8. Phan LT, Nguyen TV, Luong QC, et al. Importation and Human-to-Human Transmission of a Novel Coronavirus in Vietnam. N Engl J Med 2020;382:872-4.

9. Rothe C, Schunk M, Sothmann P, et al. Transmission of 2019-nCoV Infection from an Asymptomatic Contact in Germany. N Engl J Med 2020;382:970-1. 
10. Holshue ML, DeBolt C, Lindquist S, et al. First Case of 2019 Novel

Coronavirus in the United States. N Engl J Med 2020;382:929-36.

11. World Health Organization. Coronavirus disease 2019 (COVID-19) Situation

Report-53. March 13, 2020

(https://www.who.int/docs/default-source/coronaviruse/situation-reports/20200313-s

itrep-53-Covid-19.pdf?sfvrsn=adb3f72_2).

12. Yang W, Cao Q, Qin L, et al. Clinical characteristics and imaging manifestations of the 2019 novel coronavirus disease (COVID-19):A multi-center study in Wenzhou city, Zhejiang, China. J Infect 2020.

13. Xu XW, Wu XX, Jiang XG, et al. Clinical findings in a group of patients infected with the 2019 novel coronavirus (SARS-Cov-2) outside of Wuhan, China: retrospective case series. BMJ 2020;368:m606.

14. Chen N, Zhou M, Dong X, et al. Epidemiological and clinical characteristics of 99 cases of 2019 novel coronavirus pneumonia in Wuhan, China: a descriptive study. Lancet 2020;395:507-13.

15. Wang D, Hu B, Hu C, et al. Clinical Characteristics of 138 Hospitalized Patients With 2019 Novel Coronavirus-Infected Pneumonia in Wuhan, China. JAMA 2020.

16. Lin K, Yee-Tak Fong D, Zhu B, Karlberg J. Environmental factors on the SARS epidemic: air temperature, passage of time and multiplicative effect of hospital infection. Epidemiol Infect 2006;134:223-30.

17. World Health Organization. Clinical management of severe acute respiratory infection when novel coronavirus (2019-nCoV) infection is suspected: interim 
guidance. March 5, 2020 (https://www.who.int/docs/default-source/coronaviruse/ clinical-management-of-novel-cov.pdf).

18. National Health Commission of the People's Republic of China. Diagnosis and treatment of new coronavirus pneumonia (trial version 3).March 13, 2020

(http://www.nhc.gov.cn/xcs/zhengcwj/202001/f492c9153ea9437bb587ce2ffcbee1fa/f iles/39e7578d85964dbe81117736dd789d8f.pdf).

19. National Health Commission of the People's Republic of China. Diagnosis and treatment of new coronavirus pneumonia (trial version 7). March 13, 2020

(http://www.nhc.gov.cn/yzygj/s7653p/202003/46c9294a7dfe4cef80dc7f5912eb1989/ files/ce3e6945832a438eaae415350a8ce964.pdf).

20. Force ADT, Ranieri VM, Rubenfeld GD, et al. Acute respiratory distress syndrome: the Berlin Definition. JAMA 2012;307:2526-33.

21. Khwaja A. KDIGO clinical practice guidelines for acute kidney injury. Nephron Clinical practice 2012;120:c179-84.

22. Gao C, Wang Y, Gu X, et al. Association Between Cardiac Injury and Mortality in Hospitalized Patients Infected With Avian Influenza A (H7N9) Virus. Crit Care 2020.

23. Guan WJ, Ni ZY, Hu Y, et al. Clinical Characteristics of Coronavirus Disease 2019 in China. N Engl J Med 2020.

24. van den Oever IA, Raterman HG, Nurmohamed MT, Simsek S. Endothelial dysfunction, inflammation, and apoptosis in diabetes mellitus. Mediators Inflamm 2010;2010:792393. 
medRxiv preprint doi: https://doi.org/10.1101/2020.03.19.20038539; this version posted March 23, 2020. The copyright holder for this preprint (which was not certified by peer review) is the author/funder, who has granted medRxiv a license to display the preprint in perpetuity. All rights reserved. No reuse allowed without permission.

25. Singer G, Granger DN. Inflammatory responses underlying the microvascular dysfunction associated with obesity and insulin resistance. Microcirculation 2007; 14:375-87.

26. $\mathrm{Xu} \mathrm{Y,} \mathrm{Li} \mathrm{X,} \mathrm{Zhu} \mathrm{B,} \mathrm{et} \mathrm{al.} \mathrm{Characteristics} \mathrm{of} \mathrm{pediatric} \mathrm{SARS-CoV-2} \mathrm{infection} \mathrm{and}$ potential evidence for persistent fecal viral shedding. Nature Medicine 2020.

27. Yang X, Yu Y, Xu J, et al. Clinical course and outcomes of critically ill patients with SARS-CoV-2 pneumonia in Wuhan, China: a single-centered, retrospective, observational study. The Lancet Respiratory Medicine 2020.

28. Zhang JJ, Dong X, Cao YY, et al. Clinical characteristics of 140 patients infected with SARS-CoV-2 in Wuhan, China. Allergy 2020. 
medRxiv preprint doi: https://doi.org/10.1101/2020.03.19.20038539; this version posted March 23, 2020. The copyright holder for this preprint (which was not certified by peer review) is the author/funder, who has granted medRxiv a license to display the preprint in perpetuity. All rights reserved. No reuse allowed without permission.

Table 1 Demographic and Clinical Characteristics of Patients Infected with

Coronavirus Disease 2019 in Hainan Province

\begin{tabular}{|c|c|c|c|c|}
\hline Characteristics & $\begin{array}{l}\text { All patients } \\
\text { ( N=168 ) }\end{array}$ & $\begin{array}{l}\text { Non-severe } \\
\text { ( N=132 ) }\end{array}$ & $\begin{array}{l}\text { Severe } \\
(\mathrm{N}=36)\end{array}$ & $P$ \\
\hline \multicolumn{5}{|l|}{ Age } \\
\hline Median (IQR)-yrs & $51(36-62)$ & $49(34-60)$ & $61(50.3-68)$ & 0.002 \\
\hline Distributions - no. (\%) & & & & 0.009 \\
\hline $0-17 \mathrm{yr}$ & $8(4.8)$ & $8(6.1)$ & $0(0)$ & \\
\hline $18-49 \mathrm{yr}$ & $68(40.5)$ & $60(45.5)$ & $8(22.2)$ & \\
\hline $50-64 \mathrm{yr}$ & $59(35.1)$ & $43(32.6)$ & $16(44.4)$ & \\
\hline$\geq 65 \mathrm{yr}$ & $33(19.6)$ & $21(15.9)$ & $12(33.3)$ & \\
\hline Sex - no. (\%) & & & & 0.17 \\
\hline Male & $81(48.2)$ & $60(45.5)$ & $21(58.3)$ & \\
\hline Female & $87(51.8)$ & $72(54.5)$ & $15(41.7)$ & \\
\hline Job - no. $(\%)$ & & & & 0.01 \\
\hline Retired & $56(33.3)$ & $37(28)$ & $19(52.8)$ & \\
\hline Medical staff & $1(0.6)$ & $0(0)$ & $1(2.8)$ & \\
\hline Worker/Farmer & $23(13.7)$ & $21(15.9)$ & $2(5.6)$ & \\
\hline Service staff & $37(22)$ & $33(25)$ & $4(11.1)$ & \\
\hline Others & $51(30.4)$ & $41(31.1)$ & $10(27.8)$ & \\
\hline Sources of cases - no. $(\%)$ & & & & 0.87 \\
\hline Imported & $129(76.8)$ & $101(76.5)$ & $28(77.8)$ & \\
\hline
\end{tabular}


medRxiv preprint doi: https://doi.org/10.1101/2020.03.19.20038539; this version posted March 23, 2020. The copyright holder for this preprint (which was not certified by peer review) is the author/funder, who has granted medRxiv a license to display the preprint in perpetuity. All rights reserved. No reuse allowed without permission.

Local

$39(23.2)$

$31(23.5)$

$8(21.9)$

\section{Exposure to source of transmission}

within past 14 days - no. (\%)

Living in Wuhan or travel in Wuhan

$118(70.2)$

$93(70.5)$

$25(69.4)$

0.91

Had contact with Covid-19 patients

$51(30.4)$

$42(31.8)$

$9(25)$

0.43

Had contact with Wuhan residents

$$
52(31)
$$

$38(28.8)$

14 (38.9)

0.25

Aggregation disease

$102(60.7)$

$82(62.1)$

$20(55.6)$

0.48

Symptoms - no. (\%)

Dry cough

Expectoration

Nasal congestion

Sore throat

Rhinorrhoea

Diarrhea

Abdominal pain

Myalgia

Nausea

Vomiting

Anorexia

Dizziness

Headache

Weakness
$82(48.8)$

$54(32.1)$

$10(6)$

$19(11.3)$

$6(3.6)$

$12(7.1)$

$7(4.2)$

$14(8.3)$

$9(5.4)$

7 (4.2)

$14(8.3)$

$12(7.1)$

$14(8.3)$

47 (28)
63 (47.7)

19 (52.8)

0.59

43 (32.6)

11 (30.6)

0.82

$6(4.5)$

$4(11.1)$

0.28

$13(9.8)$

$6(16.7)$

0.40

$6(4.5)$

0 (0)

0.43

$8(6.1)$

4 (11.1)

0.5

$5(3.8)$

$2(5.6)$

1.00

$11(8.3)$

$3(8.3)$

1.00

$6(4.5)$

$3(8.3)$

0.63

$3(2.3)$

$4(11.1)$

0.06

$8(6.1)$

$6(16.7)$

0.09

8 (6.1)

$4(11.1)$

0.50

9 (6.8)

5 (13.9)

0.31

$33(25)$

14 (38.9)

0.10 


$\begin{array}{lcccr}\text { Dyspnea } & 7(4.2) & 2(1.5) & 5(13.9) & \mathbf{0 . 0 0 5} \\ \text { Arthralgia } & 2(1.2) & 2(1.5) & 0(0) & 0.62 \\ \text { Anhelation } & 22(13.1) & 15(11.4) & 7(19.4) & 0.32 \\ \text { chest tightness } & 24(14.3) & 17(12.9) & 7(19.4) & 0.32 \\ \text { Pharyngeal congestion } & 1(0.6) & 1(0.8) & 0(0) & 0.79 \\ \text { Pharyngeal discomfort } & 7(4.2) & 5(3.8) & 2(5.6) & 1.00 \\ \text { Dry throat } & 5(3) & 3(2.3) & 2(5.6) & 0.64 \\ \text { Chill } & 10(6) & 8(6.1) & 2(5.6) & 1.00 \\ \text { Shortness of breath } & 4(2.4) & 3(2.3) & 1(2.8) & 0.62 \\ \text { Hemoptysis } & 1(0.6) & 0(0) & 1(2.8) & 0.21\end{array}$

\section{Fever on admission}

Median temperature (IQR) - ${ }^{\circ} \mathbf{C} \quad 36.8(36.5-37.3) \quad 36.8(36.5-37.3) \quad 37.0(36.7-37.5) \quad \mathbf{0 . 0 4}$

$\begin{array}{lllll}\text { Patients - no. }(\%) & 110(65.5) & 82(62.1) & 28(77.8) & 0.08\end{array}$

$\begin{array}{ll}\text { Distribution of temperature - no. }(\%) & 0.15\end{array}$
$<37.5^{\circ} \mathrm{C}$
$131(78)$
$106(80.3)$
$25(69.4)$
$37.5-38.0^{\circ} \mathrm{C}$
$24(14.3)$
18 (13.6)
$6(16.7)$
$38.1-39.0^{\circ} \mathrm{C}$
$12(7.1)$
$8(6.1)$
$4(11.1)$
$>39.0^{\circ} \mathrm{C}$
$1(0.6)$
$0(0)$
$1(2.8)$

Fever during hospitalization

Patients - no. (\%)

97 (57.7)

$67(50.8)$

$30(87.5)$

$<0.001$

Distribution of temperature - no./total no. (\%) 
medRxiv preprint doi: https://doi.org/10.1101/2020.03.19.20038539; this version posted March 23, 2020. The copyright holder for this preprint (which was not certified by peer review) is the author/funder, who has granted medRxiv a license to display the preprint in perpetuity. All rights reserved. No reuse allowed without permission.

\begin{tabular}{|c|c|c|c|c|}
\hline $37.5-38.0^{\circ} \mathrm{C}$ & 38/97 (39.2) & $30 / 67(44.8)$ & $8 / 30(26.7)$ & \\
\hline $38.1-39.0^{\circ} \mathrm{C}$ & $36 / 97(37.1)$ & $26 / 67(38.8)$ & $10 / 30(33.3)$ & \\
\hline$>39.0^{\circ} \mathrm{C}$ & $12 / 97(12.4)$ & $3 / 67(4.5)$ & $9 / 30(30)$ & \\
\hline Respiratory rate, median (IQR) & $20(20-20)$ & $20(20-20)$ & $20(20-22.8)$ & 0.58 \\
\hline Heart rate, median (IQR), bpm & $82.5(76-92)$ & $80.5(75-88)$ & $92(82.3-102.3)$ & $<0.001$ \\
\hline Systolic Blood Pressure, mmHg & $124(115-136.3)$ & $123.5(115.8-135)$ & $126(112-139.5)$ & 0.80 \\
\hline Diastolic blood pressure, $\mathrm{mmHg}$ & $78(72-86)$ & $78.5(72-86)$ & $76(73-83.5)$ & 0.63 \\
\hline \multicolumn{5}{|l|}{ Comorbidities - no. (\%) } \\
\hline Hypertension & $24(14.3)$ & $13(9.8)$ & $11(30.6)$ & 0.002 \\
\hline Diabetes & $12(7.1)$ & $5(3.8)$ & $7(19.4)$ & 0.004 \\
\hline Cardiovascular disease & $12(7.1)$ & $6(4.5)$ & $6(16.7)$ & $\mathbf{0 . 0 3}$ \\
\hline Cancer & $2(1.2)$ & $2(1.5)$ & $0(0)$ & 0.62 \\
\hline Chronic kidney disease & $1(0.6)$ & $0(0)$ & $1(2.8)$ & 0.21 \\
\hline Chronic liver disease & $6(3.6)$ & $3(2.3)$ & $3(8.3)$ & 0.22 \\
\hline Lung disease & $10(6)$ & $6(4.5)$ & $4(11.1)$ & 0.28 \\
\hline \multicolumn{5}{|l|}{ Chronic bronchitis/asthma /other } \\
\hline upper respiratory diseases & $2(1.2)$ & $2(1.5)$ & $0(0)$ & 0.62 \\
\hline Thyroid disease & $2(1.2)$ & $1(0.8)$ & $1(2.8)$ & 0.38 \\
\hline Lithiasis & $2(1.2)$ & $1(0.8)$ & $1(2.8)$ & 0.38 \\
\hline
\end{tabular}


Table 2 Radiographic and Laboratory Findings of Patients Infected with Coronavirus Disease 2019 in Hainan Province

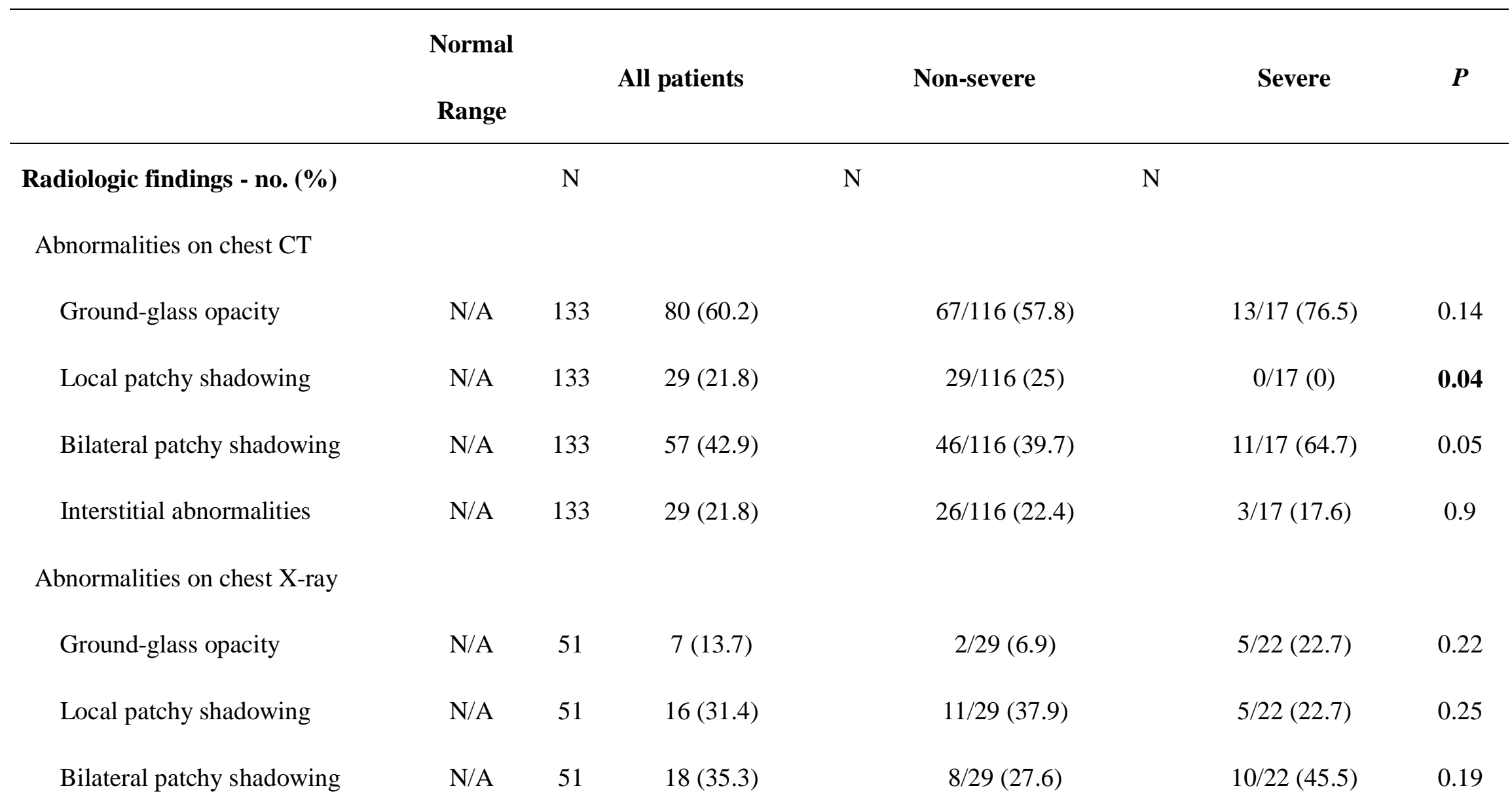




\section{Laboratory findings}

\begin{tabular}{|c|c|c|c|c|c|c|c|c|}
\hline White blood cell count, $\times 10^{9} / \mathrm{L}$ & $3.5-9.5$ & 167 & $4.8(4.0-6.3)$ & 132 & $4.7(3.9-5.9)$ & 35 & $5.6(4.3-7.8)$ & 0.006 \\
\hline Increased - no. $(\%)$ & & 167 & $8(4.8)$ & 132 & $2(1.5)$ & 35 & $6(21.9)$ & \\
\hline Decreased - no. (\%) & & 167 & $40(24)$ & 132 & $36(27.3)$ & 35 & $4(21.9)$ & \\
\hline Platelet count, $\times 10^{9} / \mathrm{L}$ & $125-350$ & 167 & $189(147-249)$ & 132 & $200.5(152-253)$ & 35 & $152(117-210)$ & 0.005 \\
\hline Increased - no. $(\%)$ & & 167 & $17(10.2)$ & 132 & $15(11.4)$ & 35 & $2(21.9)$ & \\
\hline Decreased - no. $(\%)$ & & 167 & $10(6)$ & 132 & $5(3.8)$ & 35 & $5(21.9)$ & \\
\hline Lymphocyte ratio, $\%$ & $20-50$ & 166 & $26.2(17.2-31.8)$ & 131 & $27.9(20.8-34.5)$ & 35 & $16.8(8.2-21.5)$ & $<0.001$ \\
\hline Neutrophil ratio, $\%$ & $40-75$ & 167 & $64(57.8-73.1)$ & 132 & $62.1(55.6-69.2)$ & 35 & $74.8(67.6-83.1)$ & $<0.001$ \\
\hline Lymphocyte count, $\times 10^{9} / \mathrm{L}$ & $1.1-3.2$ & 165 & $1.2(0.8-1.5)$ & 130 & $1.3(0.9-1.6)$ & 35 & $0.8(0.6-1.2)$ & $<0.001$ \\
\hline Increased - no. $(\%)$ & & 165 & $3(1.8)$ & 130 & $3(2.3)$ & 35 & $0(0)$ & \\
\hline Decreased - no. (\%) & & 165 & $72(43.6)$ & 130 & $49(37.7)$ & 35 & $23(65.7)$ & \\
\hline
\end{tabular}




\begin{tabular}{|c|c|c|c|c|c|c|c|c|}
\hline Monocyte count, $\times 10^{9} / \mathrm{L}$ & $0.1-0.6$ & 165 & $0.4(0.3-0.5)$ & 130 & $0.4(0.3-0.5)$ & 35 & $0.4(0.3-0.6)$ & 0.49 \\
\hline Neutrophil count, $\times 10^{9} / \mathrm{L}$ & $1.8-6.3$ & 166 & $3.1(2.3-4.3)$ & 131 & $2.9(2.2-3.9)$ & 35 & $4.2(3.0-7.7)$ & $<0.001$ \\
\hline Increased - no. (\%) & & 166 & $10(6)$ & 131 & $3(2.3)$ & 35 & $7(21.9)$ & \\
\hline Decreased - no. (\%) & & 166 & $19(11.4)$ & 131 & $16(12.2)$ & 35 & $3(21.9)$ & \\
\hline Eosinophil count, $\times 10^{9} / \mathrm{L}$ & $0.02-0.52$ & 165 & $0.03(0-0.1)$ & 130 & $0.04(0.01-0.1)$ & 35 & $0(0-0.02)$ & $<0.001$ \\
\hline C-reactive protein, $\mathrm{mg} / \mathrm{L}$ & $0-8.2$ & 97 & $17(3.8-35.9)$ & 69 & $11.8(1.2-26.2)$ & 28 & $33.8(18.5-64.4)$ & $<0.001$ \\
\hline Increased - no. $(\%)$ & & 97 & $65(67)$ & 69 & $40(58)$ & 28 & $25(21.9)$ & \\
\hline Prothrombin time, $\mathrm{s}$ & $9.8-13.2$ & 95 & $11.6(11-12.3)$ & 69 & $11.6(11-12.2)$ & 26 & $11.7(11.2-12.7)$ & 0.22 \\
\hline Increased - no. (\%) & & 95 & $10(10.5)$ & 69 & $5(7.2)$ & 26 & $5(21.9)$ & \\
\hline \multicolumn{9}{|c|}{ Activated partial thromboplastin } \\
\hline & $21-36$ & 96 & $29.1(26.4-32.5)$ & 69 & $29.2(26.6-32.7)$ & 27 & $28.9(25.3-31.8)$ & 0.69 \\
\hline \multicolumn{9}{|l|}{ ime, $s$} \\
\hline Increased - no. $(\%)$ & & 96 & $8(8.3)$ & 69 & $4(5.8)$ & 27 & $4(21.9)$ & \\
\hline D-dimer, $\mathrm{mg} / \mathrm{L}$ & $<0.5$ & 46 & $0.3(0.2-0.7)$ & 31 & $0.3(0.2-0.5)$ & 15 & $0.6(0.3-2.6)$ & 0.003 \\
\hline
\end{tabular}




\begin{tabular}{|c|c|c|c|c|c|c|c|c|}
\hline Increased - no. $(\%)$ & & 46 & $14(30.4)$ & 31 & $7(22.6)$ & 15 & $7(46.7)$ & \\
\hline Potassium, mmol/L & $3.5-5.3$ & 124 & $3.8(3.5-4.1)$ & 93 & $3.8(3.5-4.1)$ & 31 & $3.7(3.4-4)$ & 0.64 \\
\hline Sodium, mmol/L & $137-147$ & 124 & $138.8(136-142.2)$ & 93 & $139(136.5-142.3)$ & 31 & $137(132-142)$ & 0.12 \\
\hline Chloride, $\mathrm{mmol} / \mathrm{L}$ & $99-110$ & 123 & $104.1(102-106.4)$ & 92 & $104.8(103-106.6)$ & 31 & $103(100-106)$ & 0.02 \\
\hline Calcium, mmol/L & $2.2-2.7$ & 118 & $2.3(2.2-2.4)$ & 88 & $2.3(2.2-2.4)$ & 30 & $2.2(2.1-2.3)$ & 0.03 \\
\hline Phosphorus, mmol/L & $0.85-1.51$ & 95 & $1.02(0.84-1.32)$ & 69 & $1.05(0.88-1.35)$ & 26 & $0.92(0.79-1.12)$ & 0.06 \\
\hline Magnesium, mmol/L & $0.75-1.02$ & 101 & $0.87(0.79-0.96)$ & 75 & $0.87(0.79-0.97)$ & 26 & $0.86(0.79-0.93)$ & 0.53 \\
\hline Blood urea nitrogen, $\mathrm{mmol} / \mathrm{L}$ & $3.6-9.5$ & 122 & $3.7(2.9-4.5)$ & 93 & $3.6(2.9-4.3)$ & 29 & $4.1(2.9-7.0)$ & 0.05 \\
\hline Increased - no. (\%) & & 122 & $4(3.3)$ & 93 & $0(0)$ & 29 & $4(21.9)$ & \\
\hline Decreased - no. $(\%)$ & & 122 & $24(19.7)$ & 93 & $19(20.4)$ & 29 & $5(21.9)$ & \\
\hline Creatinine, $\mu \mathrm{mol} / \mathrm{L}$ & $57-111$ & 118 & $62(49-75.1)$ & 88 & $62.1(49.8-72.0)$ & 30 & $57.3(48.6-87.1)$ & 0.69 \\
\hline Increased - no. (\%) & & 118 & $4(3.4)$ & 88 & $0(0)$ & 30 & $4(13.3)$ & \\
\hline Decreased - no. (\%) & & 118 & $8(6.8)$ & 88 & $5(5.7)$ & 30 & $3(10)$ & \\
\hline
\end{tabular}




\begin{tabular}{|c|c|c|c|c|c|c|c|c|}
\hline Total protein, g/L & $65-85$ & 113 & $65(60.2-68.6)$ & 83 & $66(60.7-69.2)$ & 30 & $62.3(57.3-67.0)$ & 0.01 \\
\hline Decreased - no. (\%) & & 113 & $49(43.4)$ & 83 & $30(36.1)$ & & $19(63.3)$ & \\
\hline Albumin, g/L & $40-55$ & 115 & $41.7(38.8-45)$ & 84 & $42.4(39.9-47.1)$ & 31 & $40.4(33.2-42.2)$ & 0.001 \\
\hline Increased - no. (\%) & & 115 & $3(2.6)$ & 84 & $2(2.4)$ & 31 & $1(3.2)$ & \\
\hline Decreased - no. (\%) & & 115 & $32(27.8)$ & 84 & $18(21.4)$ & 31 & $14(45.2)$ & \\
\hline Alanine aminotransferase, U/L & $9-50$ & 112 & $22.6(16-35)$ & 81 & $20.9(14.9-33)$ & 31 & $29(16.6-40.8)$ & 0.08 \\
\hline Increased - no. (\%) & & 112 & $9(8)$ & 81 & $5(6.2)$ & 31 & $4(12.9)$ & \\
\hline Decreased - no. (\%) & & 112 & $6(5.4)$ & 81 & $4(4.9)$ & 31 & $2(6.5)$ & \\
\hline Aspartate aminotransferase, U/L & $15-40$ & 104 & $25.3(20-38.63)$ & 75 & $24.3(20-31)$ & 29 & $37.1(24-51.5)$ & 0.004 \\
\hline Increased - no. (\%) & & 104 & $18(17.3)$ & 75 & $7(9.3)$ & 29 & $11(37.9)$ & \\
\hline Decreased - no. $(\%)$ & & 104 & $2(1.9)$ & 75 & $1(1.3)$ & 29 & $1(3.4)$ & \\
\hline Lactate dehydrogenase, U/L & $120-250$ & 93 & $207(169.5-274.5)$ & 67 & $188(164-248)$ & 26 & $256.5(211.3-413.8)$ & 0.001 \\
\hline Total bilirubin, $\mathrm{mmol} / \mathrm{L}$ & $0-26$ & 112 & $8.8(6.3-13.4)$ & 81 & $8.2(5.7-10.6)$ & 31 & $10.5(8.4-14.6)$ & 0.004 \\
\hline
\end{tabular}




$\begin{array}{lcccccccc}\text { Creatine kinase, U/L } & 50-310 & 109 & 68(44.5-113.5) & 80 & 68(47-107) & 29 & 75(34-144) & 0.92 \\ \quad \text { Increased - no. (\%) } & & 109 & 7(6.4) & 80 & 3(3.8) & 29 & 4(13.8) \\ \text { Decreased - no. (\%) } & & 109 & 9(8.3) & 80 & 7(8.8) & 29 & 2(6.9) \\ \text { Creatine kinase-MB, U/L } & 0-24 & 109 & 12(8-15.8) & 80 & 12.1(9.0-15.7) & 29 & 9.9(6.5-18.3) & 0.35 \\ \text { Procalcitonin, ng/mL } & <0.046 & 103 & 0.04(0.026-0.069) & 81 & 0.038(0.02-0.06) & 22 & 0.067(0.032-0.257) & \mathbf{0 . 0 0 7} \\ \quad & & 103 & 26(25.2) & 81 & 19(23.5) & 22 & 7(31.8)\end{array}$

Data are presented as frequency (percentage) and median (IQR) unless otherwise indicated. Increased means over the upper limit of the normal range and decreased means below the lower limit of the normal range. 
Table 3 Complications, Treatments, and Clinical Outcomes of Patients Infected with Coronavirus Disease 2019 in Hainan Province

\begin{tabular}{|c|c|c|c|c|}
\hline Variable & $\begin{array}{l}\text { All patients } \\
\text { ( } N=168)\end{array}$ & $\begin{array}{l}\text { Non-severe } \\
\text { ( N=132 ) }\end{array}$ & $\begin{array}{l}\text { Severe } \\
(\mathrm{N}=36)\end{array}$ & $\boldsymbol{P}$ \\
\hline Clinical outcome- no. $(\%)$ & & & & $<0.001$ \\
\hline Discharged & $160(95.2)$ & $130(98.5)$ & $30(83.3)$ & \\
\hline Died & $6(3.6)$ & $0(0)$ & $6(16.7)$ & \\
\hline Remained in hospital & $2(1.2)$ & $2(1.5)$ & $2(5.6)$ & \\
\hline \multicolumn{5}{|l|}{ Course- Median (IQR), days } \\
\hline Time from onset of symptoms to first & $1(0-4)$ & $1(0-4)$ & $2(0-4.8)$ & $<0.001$ \\
\hline hospital visit $(\mathrm{N}=168)$ & & & & \\
\hline Time from onset of symptoms to & & & & \\
\hline diagnosis $(\mathrm{N}=168)$ & $4.5(2-7)$ & $4(1.3-7)$ & $6(2.3-11.5)$ & $<0.001$ \\
\hline Time from onset of symptoms to & $5(2-7)$ & $4.5(2-7)$ & $7(3-10)$ & $<0.001$ \\
\hline hospital admission $(\mathrm{N}=168)$ & & & & \\
\hline Time from onset of symptoms to severe & & & & \\
\hline illness $(\mathrm{N}=36)$ & $11(7-13)$ & N/A & N/A & $\mathrm{N} / \mathrm{A}$ \\
\hline Time from onset of symptoms to & $22(17-27)$ & $\mathrm{N} / \mathrm{A}$ & N/A & $\mathrm{N} / \mathrm{A}$ \\
\hline discharge $(\mathrm{N}=160)$ & & & & \\
\hline Time from hospital admission to & & & & \\
\hline discharge $(N=160)$ & $17(12-21)$ & N/A & N/A & N/A \\
\hline Time from onset of symptoms onset to & $17(10.5-37.3)$ & N/A & N/A & N/A \\
\hline
\end{tabular}


death $(\mathrm{N}=6)$

Time from hospital admission to death

$13(1.5-28.3) \quad$ N/A N/A N/A

$(\mathrm{N}=6)$

\section{Positive RT-PCR test after discharge-}

no./total no. $(\%)$

$20 / 160(12.5) \quad 18 / 130(13.8) \quad 2 / 30(6.7) \quad 0.44$

Complications- no. (\%)

Acute cardiac injury

Acute respiratory distress syndrome

Acute kidney injury

Sepsis

Acute lung injury

Secondary bacterial pneumonia

Arrhythmia

Epilepsy

Shock

Secondary fungal infection

Multiple organ dysfunction

Respiratory failure

Disseminated intravascular coagulation

Gastrointestinal flora disorder

Hypoproteinemia

Electrolyte disturbances

$$
4 \text { (2.4) }
$$

$17(10.1)$

$6(3.6)$

$4(2.4)$

$12(7.1)$

$2(1.2)$

$2(1.2)$

$7(4.2)$

$2(1.2)$

$2(1.2)$

$10(6)$

$2(1.2)$

$1(0.6)$

$3(1.8)$

$3(1.8)$
0 (0)

$1(0.8)$

$0(0)$

$0(0)$

$0(0)$

$2(1.5)$

$0(0)$

$0(0)$

$0(0)$

$0(0)$

$0(0)$

$0(0)$

$3(8.3)$

$<0.001$

$0(0)$

$1(2.8)$

0.04

0 (0)

$1(2.8)$

0.22

0 (0)

$3(8.3)$

0.009

$0(0)$

$3(8.3)$

0.009 
Acute liver injury

Digestive tracthemorrhage

Pneumothorax

Metabolic disorder

Treatments- no. $(\%)$

Nasal cannula oxygen

Non-invasive ventilator assisted breathing

Trachea cannula

Tracheotomy

Mask oxygen inhalation

Cardio-pulmonary resuscitation

Antibiotics therapy

Antiviral therapy

Antifungal therapy

Immunopotentiator

Glucocorticoid

Acid suppression drugs

Expectorant and antitussive drugs

Intestinal flora regulating drugs

Gastric mucosa repair agent

Immunosuppressor

Pseudoepinephrine
$4(2.4)$

$4(2.4)$

$2(1.2)$

$2(1.2)$

$97(57.7)$

$13(7.7)$

$10(6)$

$2(1.2)$

$3(1.8)$

$5(3)$

$119(70.8)$

$155(92.3)$

$8(4.8)$

$91(54.2)$

$27(16.1)$

$32(19)$

$22(13.1)$

$71(42.3)$

$17(10.1)$

$2(1.2)$

$2(1.2)$
$0(0)$

$0(0)$

$0(0)$

$0(0)$

$2(5.6)$

0.04

$2(5.6)$

0.04
$4(11.1) \quad \mathbf{0 . 0 0 2}$

$4(11.1) \quad \mathbf{0 . 0 0 2}$

$70(53)$

$27(75)$

0.02

$2(1.5)$

$11(30.6)$

$<0.001$

$0(0)$

$10(27.8)$

$<0.001$

$0(0)$

$2(5.6)$

0.04

$0(0)$

$3(8.3)$

0.009

$0(0)$

5 (13.9)

$<0.001$

$87(65.9) \quad 32(88.9)$

0.007

0.37

$120(90.9)$

35 (97.2)

0.001

$2(1.5)$

$6(16.7)$

$26(72.2)$

0.01

$65(49.2) \quad 26(72.2)$

$19(52.8)$

$<0.001$

$8(6.1)$

$16(12.1)$

$16(44.4)$

$<0.001$

$10(7.6)$

$12(33.3)$

$<0.001$

$52(39.4)$

19(52.8)

0.15

$10(7.6)$

7 (19.4)

0.08

$0(0)$

$2(5.6)$

0.04

$0(0)$

$2(5.6)$

0.04 
medRxiv preprint doi: https://doi.org/10.1101/2020.03.19.20038539; this version posted March 23, 2020. The copyright holder for this preprint (which was not certified by peer review) is the author/funder, who has granted medRxiv a license to display the preprint in perpetuity. All rights reserved. No reuse allowed without permission.

\begin{tabular}{lcccc} 
M-receptor inhibitors & $1(0.6)$ & $0(0)$ & $1(2.8)$ & 0.22 \\
Nitrates & $1(0.6)$ & $0(0)$ & $1(2.8)$ & 0.22 \\
$\mathrm{Ca}^{2+}$-receptor blocker & $7(4.2)$ & $1(0.8)$ & $6(16.7)$ & $<\mathbf{0 . 0 0 1}$ \\
$\beta$-blocker & $3(1.8)$ & $3(2.3)$ & $0(0)$ & 0.48 \\
Traditional Chinese medicine & $30(17.9)$ & $25(18.9)$ & $5(13.9)$ & 0.40 \\
\hline
\end{tabular}

